This item was submitted to Loughborough's Research Repository by the author.

Items in Figshare are protected by copyright, with all rights reserved, unless otherwise indicated.

\title{
The influence of seat backrest angle on perceived discomfort during exposure to vertical whole-body vibration
}

PLEASE CITE THE PUBLISHED VERSION

http://dx.doi.org/10.1080/00140139.2012.684889

PUBLISHER

(c) Taylor \& Francis Ltd.

VERSION

AM (Accepted Manuscript)

LICENCE

CC BY-NC-ND 4.0

\section{REPOSITORY RECORD}

Paddan, G.S., Neil J. Mansfield, C.I. Arrowsmith, Andrew N. Rimell, S.K. King, and S.R. Holmes. 2019. "The Influence of Seat Backrest Angle on Perceived Discomfort During Exposure to Vertical Whole-body Vibration". figshare. https://hdl.handle.net/2134/12137. 
This item was submitted to Loughborough's Institutional Repository (https://dspace.lboro.ac.uk/) by the author and is made available under the following Creative Commons Licence conditions.

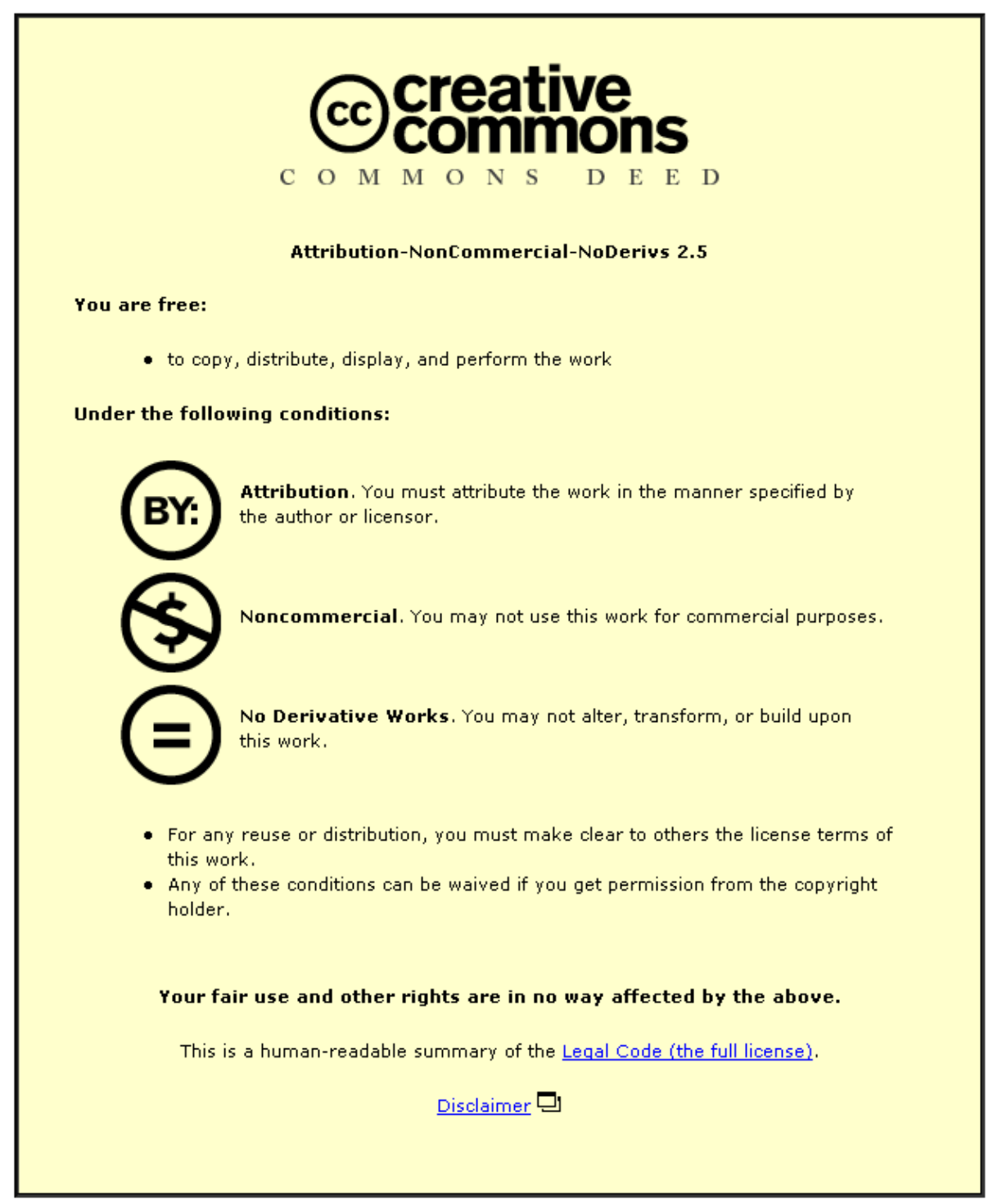

For the full text of this licence, please go to: http://creativecommons.org/licenses/by-nc-nd/2.5/ 
The influence of seat backrest angle on perceived discomfort during exposure to vertical whole-body vibration

G.S. Paddan ${ }^{a}$, NJ. Mansfield ${ }^{b}$, C.I. Arrowsmith ${ }^{c}$, A.N. Rimell ${ }^{b}$, S.K. King ${ }^{c}$ and S.R. Holmes ${ }^{c}$

${ }^{a}$ Institute of Naval Medicine, Gosport, UK; ${ }^{b}$ Loughborough Design School, Loughborough University, Loughborough, UK;

${ }^{c} Q$ inetiQ, Farnborough, UK

(Received 8 February 2012; final version received 6 April 2012)

\section{The influence of seat backrest angle on perceived discomfort during exposure to vertical whole-body vibration}

G.S. Paddan ${ }^{1}$, C.I. Arrowsmith ${ }^{2}$, A.N. Rimell ${ }^{3}$, S.K. King ${ }^{2}$, N.J. Mansfield ${ }^{3}$, and S.R. Holmes ${ }^{2}$

${ }^{1}$ Institute of Naval Medicine, Gosport, UK

${ }^{2}$ QinetiQ, Farnborough, UK

${ }^{3}$ Loughborough Design School, Loughborough University, Loughborough, UK

Corresponding Author

Dr Gurmail S Paddan

Head of Acoustics and Vibration

Institute of Naval Medicine

Alverstoke, Gosport

Hampshire, PO12 2DL

Tel: +44(0)239276 8080

Email: inm-ems-acvibhead@mod.uk 



\title{
The influence of seat backrest angle on perceived discomfort during exposure to vertical whole-body vibration
}

\begin{abstract}
National and International Standards (e.g. BS 6841 and ISO 2631-1) provide methodologies for the measurement and assessment of whole-body vibration in terms of comfort and health. The EU Physical Agents (Vibration) Directive (PAVD) provides criteria by which vibration magnitudes can be assessed. However, these standards only consider upright seated $\left(90^{\circ}\right)$ and recumbent $\left(0^{\circ}\right)$ backrest angles, and do not provide guidance for semi-recumbent postures. This paper reports an experimental programme that investigated the effects of backrest angle on comfort during vertical whole-body vibration. The series of experiments showed that a relationship exists between seat backrest angle, whole-body vibration frequency and perceived levels of discomfort. The recumbent position $\left(0^{\circ}\right)$ was the most uncomfortable and the semi-recumbent positions of $67.5^{\circ}$ and $45^{\circ}$ were the least uncomfortable. A new set of frequency weighting curves are proposed which use the same topology as the existing BS and ISO standards. These curves could be applied to those exposed to whole-body vibration in semirecumbent postures to augment the existing standardised methods.
\end{abstract}

Keywords: whole-body vibration, human comfort, backrest angle

Running header: "Backrest angle and whole-body vibration”

Relevance statement

Current vibration standards provide guidance for assessing exposures for seated, standing and recumbent positions, but not for semi-recumbent postures. This paper reports new experimental data systematically investigating the effect of backrest angle on discomfort experienced. It demonstrates that most discomfort is caused in a recumbent posture and that least was caused in a semi-recumbent posture. 


\section{Introduction}

The majority of whole-body vibration exposures occur in transport environments where the dominant motion is often in the vertical direction with vibration occurring in a frequency range of 0.2 to $20 \mathrm{~Hz}$ (e.g. passenger transport, earth-moving and industrial machinery, agricultural and forestry machines, military vehicles). The vertical biomechanical response of the human body shows a resonance at about 4 to $5 \mathrm{~Hz}$ which coincides with the frequencies where people are most sensitive in psychophysical tests. The exposure of the seated or standing human to whole-body vibration, especially at frequencies in the human resonance range can have a variety of detrimental effects on perceived comfort and health (BS 6841, 1987; ISO 2631-1, 1997).

Currently, two standards BS 6841 (1987) and ISO 2631-1 (1997), provide methodologies for the measurement and assessment of human response to whole-body vibration in terms of health, comfort, vision and manual control. The standards define frequency weightings for application to vibration at the seat, floor and backrest in the translational and rotational axes. For assessments of health or comfort, the standards provide different methods of dealing with complex multi-axis vibration (Mansfield, 2005), based on calculations of the vibration dose value (VDV) or the root-mean-square (r.m.s.) of the frequency weighted acceleration and suggest criteria by which the quantities can be evaluated. Although the standards provide specific guidance for assessing those in seated, standing and recumbent positions, there is no suggested strategy to take into account semi-recumbent postures that are experienced by drivers of, for example, military vehicles, patients being transported by ambulance, some longreach excavators used in demolition, race-car drivers, and passenger transportation where seats recline to facilitate sleep (e.g. long-haul air travel, some trains, some ships). 
The effect of whole-body vibration exposure on comfort and health is dependent on a number of factors: the frequency, duration and magnitude of vibration, the position at which contact between the body and vibration occurs, vibration waveform and the posture and orientation of the body (Mansfield, 2005). Changes in posture result in changes in the transmission of vibration from the seat to the head and body (Griffin et al., 1979; Paddan and Griffin, 1988). In many environments postures are dictated by seating, workspace configuration or specialised tasks, although seating can also be used for vibration isolation (Corbridge et al., 1989).

Short term exposure to whole-body vibration can result in physiological changes. Researchers have reported cardiovascular responses (heart rate, respiration rate, blood pressure, and oxygen intake) during exposure to moderate vibration $2-20 \mathrm{~Hz}$ (Guignard, 1985). High magnitudes of vertical vibration (amplitudes of 1.5g), in the frequency range of $1-15 \mathrm{~Hz}$ for 15 minutes have been shown to result in the subjects experiencing symptoms of chest pain (Magid et al., 1960). Long term whole-body vibration has been proposed as a causal factor in the development of the lumbar spine disorders and back pain in general (Ozkaya et al., 1996; Zerlett, 1986; Bovenzi and Zadini, 1992). Studies by Magnusson and Pope (1998) on the epidemiology and biomechanics of working postures, reported that no single posture could be maintained for a long period of time without considerable discomfort. Lack of body movement leads to accumulation of metabolites, which leads to an acceleration of the degeneration of the discs and increases the risks of disk herniation. Most importantly the authors concluded that an inclined backrest reduces the effects of vibration, as it reduces the disc pressure.

There are no known studies that have made a specific link between health effects, vibration and posture. Stayner (2001) highlighted that although it is possible to 
associate back pain with an occupation, it is far more difficult to identify which aspect of the occupation is the cause of the pain. It is unlikely, therefore, that epidemiological data can provide a basis for establishing relative health risks between any pathogen that might be present for those working in reclined postures. Nevertheless, epidemiological studies show that those employed in sectors with high magnitudes of vibration tend to have higher prevalence of back pain (Bovenzi and Betta, 1994; Bovenzi and Hulshof, 1998; Mehta and Tewari, 2000; Mansfield and Marshall, 2001) although it is not necessarily the vibration that causes the pain.

There is a large individual variability in subjective assessments of discomfort during exposure to whole-body vibration. Studies have shown that the variation in subjective assessment may be due to the physical size of the participants, in that large males and female participants tend to be less sensitive to low frequencies (less than 6.3 $\mathrm{Hz}$ ) and more sensitive to higher frequencies of vertical vibration (Griffin et al., 1982). Other sources of individual variation include expectation, experience and context.

It has been suggested that by reclining the crew in military armoured vehicles, the effects of vibration will reduce, and the resulting reduction of the physical profile of the vehicle could make the vehicle less detectable to the enemy. The implications of this are that crew will be required to perform a number of tasks in a reclined posture and stay in that posture for prolonged periods of time. However, as typical tasks undertaken by crew require extended periods of sustained vigilance, the human cost of discomfort should not be overlooked. Previous studies have shown that discomfort ratings and fatigue significantly increase with reclination (towards the recumbent) for long duration tasks (80 to 240 minutes), even with no vibration exposure (Thody et al., 1993; Edwards et al., 1994; Edmonds, 1994). Causes of discomfort can be attributed to secondary biomechanical considerations rather than directly to the posture: lifting the 
head whilst reclined to view a display or working with upper limbs above shoulder level were both considered to generate unacceptable postural loads. If these postures are combined with vibration exposure, then discomfort might develop more rapidly.

The EU Physical Agents (Vibration) Directive (PAVD) (European Commission 2002 Directive 2002/44/EC) is implemented in all Member States in Europe and, for the first time, introduced limits on the vibration exposures for workers. Central to the Directive is the requirement to assess and minimise risks with vibration exposure. If vibration exposure is considered to constitute a risk, or if it exceeds the 'daily exposure action value' of $0.5 \mathrm{~ms}^{-2} A(8)$ measured according to ISO 2631-1 (1997), then some form of action must be taken to minimise those risks. The Directive is clear that a holistic approach is required such that, for example, the design and layout of workspaces is optimised. As ISO 2631-1 (1997) does not provide guidance for assessment of those exposed to whole-body vibration in semi-reclined postures, it is possible that the assessment may generate results that do not reflect the true risk for the operator exposed to vibration when seated in such a posture. Risk assessments that are too conservative may result in an unnecessary reduction in individual exposure times, and impact adversely on worker productivity; assessments that underestimate the risk may result in an unnecessary increase in risk of whole-body vibration injury.

This paper reports a research programme that was designed to identify the relative sensitivity of the human body to vibration of different frequencies and at different backrest angles, with a view to proposing new frequency weightings that could be used to augment comfort or risk assessments of those exposed to vibration in reclined postures. This study represents the second part of a 2-part experiment looking at the effects of vibration on performance (Paddan et al., 2012) and discomfort. 


\section{Method}

\subsection{Design}

The study comprised two main experimental phases. Phase I investigated the effects of sinusoidal, vertical whole-body vibration at frequencies of $2 \mathrm{~Hz}, 4 \mathrm{~Hz}, 8 \mathrm{~Hz}, 16 \mathrm{~Hz}, 32$ $\mathrm{Hz}$ and $64 \mathrm{~Hz}$, on perceived comfort at each of 5 backrest angles: $0^{\circ}$ (recumbent), 22.5, $45^{\circ}, 67.5^{\circ}$ and $90^{\circ}$ (upright), see Figure 1 . Phase II investigated the effects of changes in backrest angle on perceived comfort during exposure to $8 \mathrm{~Hz}$ of vertical whole-body vibration. Phase II followed Phase I. The overall aim of the study was to establish whether seat backrest angle had any effect on perceived comfort, and to use the data to generate new frequency weighting curves. The design of the experiment was approved by the QinetiQ Ethics Committee under a generic laboratory whole-body vibration exposure protocol.

Figure 1 about here

\subsection{Participants}

Twenty participants (10 male, 10 female) took part in the experiment and participated in both experimental phases. The mean age of the male participants was 30.3 years (stdev = 9.7 years, range $21-53$ years), mean weight was $78.0 \mathrm{~kg}$ (stdev = $10.5 \mathrm{~kg}$, range 61$93 \mathrm{~kg}$ ), and mean height was $1.78 \mathrm{~m}$ (stdev $=0.07 \mathrm{~m}$, range $1.67-1.85 \mathrm{~m}$ ). The mean age of the female participants was 32.1 years (stdev $=9.0$ years, range $22-47$ years), mean weight was $64.8 \mathrm{~kg}$ (stdev = $8.6 \mathrm{~kg}$, range 53-83 kg), and mean height was 1.69 $\mathrm{m}($ stdev $=0.07 \mathrm{~m}$, range $1.63-1.87 \mathrm{~m})$. 


\subsection{Apparatus}

A man-rated vertical vibration simulator with a capacity of displacements up to $\pm 0.9 \mathrm{~m}$ was used to generate the vibration stimuli. It can be programmed to accept vertical vibrations generated by laboratory instruments or derived from recorded vehicle data. The vibration simulator has a velocity limit of $1.5 \mathrm{~ms}^{-1}$, an acceleration limit of $30 \mathrm{~ms}^{-2}$, and a frequency range of 0 to $50 \mathrm{~Hz}$.

An adjustable seat was mounted on the platform of the vertical vibration simulator (see Figure 2). The main frame for the adjustable seat used for the trial was of a rigid wooden construction. The seat measured $2.0 \times 0.8 \times 1.5 \mathrm{~m}$ high with backrest fully upright and incorporated an adjustable footrest, a 3-point safety harness, a chest strap and a motorised backrest that could be driven remotely to any angle between $0^{\circ}$ (recumbent) and $90^{\circ}$ (upright) (see Figure 2). The seat surface was covered in high friction $1 \mathrm{~mm}$ thick foam rubber and the participants had the use of a small head cushion measuring $0.22 \times 0.15 \times 0.35 \mathrm{~m}$. The acceleration at the base of the seat was measured using an Endevco Q-Flex QA-116-15 servo accelerometer. Additional orthogonal acceleration measurements were also taken from the mid-point on the rear of the backrest using Endevco 7265-10 piezo-resistive accelerometers. Participant intercom and emergency stop controls were also provided.

Figure 2 about here

\subsection{Procedure}

The participants attended the laboratory on a total of eight occasions. The first visit comprised a calibration and familiarisation session. The nature of the trial was 
explained and informed, written consent obtained. The participants were exposed to all of the sinusoidal stimuli to be used in the trial, that had frequencies of $2 \mathrm{~Hz}, 4 \mathrm{~Hz}, 8 \mathrm{~Hz}$, $16 \mathrm{~Hz}, 32 \mathrm{~Hz}$ and $64 \mathrm{~Hz}$, a magnitude of $2 \mathrm{~ms}^{-2}$ r.m.s. and a duration 10 seconds. Each stimulus had a $500 \mathrm{~ms}$ linear taper at the start and end. Exposure of the participants to these stimuli allowed the output of the vertical oscillator to be calibrated to each individual. In addition, this allowed the participants to ascertain the range of wholebody vibration that they would be exposed to. This exposure was repeated at the start of each experimental session to help re-familiarise participants with their assessment criteria. In addition, on the first visit a short dummy run was undertaken. The participants were exposed to two randomly selected pairs of stimuli, presented to the participant in the same manner used in the main experiment to familiarise the participant with the trial methodology and subjective comfort rating criteria.

Immediately after the presentation of each pair of whole-body vibration stimuli, the participants were asked to give a subjective comfort rating for the comparator stimulus relative to the reference stimulus, where the reference stimulus was always equal to $100 \%$. If the participants believed the comparator stimulus was more uncomfortable than the reference, they gave a rating above $100 \%$. If they believed it was more comfortable than the reference, they gave a rating below 100\%. Participants were allowed to determine their own upper and lower limits.

Between one and five days following the familiarisation session the participants attended the laboratory for the first of five sessions comprising Phase I of the trial. For each session the participants were exposed to whole-body vibration stimuli whilst seated in one of five backrest angles: $0^{\circ}$ (recumbent), $22.5^{\circ}, 45^{\circ}, 67.5^{\circ}$ and $90^{\circ}$ (upright). The order of backrest seating angle for each participant was determined by a 
Latin square design. Participants completed the main Phase I trials over five sequential days at the same time of day for each individual.

On arrival at the laboratory, participants sat on the seat at the appropriate backrest angle. The footrest and the participant's feet were positioned so that the leg angle at the knee was fixed at $120^{\circ}$ for all conditions. The participants were then secured to the seat by the 3-point harness, and headphones placed on the head and the headrest adjusted. The headphones allowed 2-way communication with the experimenter and also conveyed pink noise (65 $\mathrm{dB}(\mathrm{A})$ at the ear) to mask the noise of the vertical vibration simulator in operation.

The tests comprised twelve pairs of stimuli that were each repeated three times: a reference and a comparator stimulus. Frequency combinations used were $2 \mathrm{~Hz}$ (reference) \& 2 Hz (comparator), 2 \& 4 Hz, 2 \& 8 Hz, 2 \& 16 Hz, 2 \& 32 Hz, 2 \& 64 $\mathrm{Hz}$ and $16 \mathrm{~Hz}$ (reference) \& $2 \mathrm{~Hz}$ (comparator), 16 \& 4 Hz, 16 \& 8 Hz, 16 \& 16 Hz, 16 \& $32 \mathrm{~Hz}$, and 16 \& $64 \mathrm{~Hz}$. There was a 1-second gap between the reference and comparator. An auditory tone, to indicate the start of each pair was sounded immediately prior to the onset of the reference stimulus. There was a 20-second gap between each pair of stimuli, during which time the participant was asked to provide their comfort rating. There was a 2-minute rest period between each of the three sets of twelve stimulus pairs. The randomisations of the pairs and timing of the onset of stimuli were controlled by custom-written control software.

It took approximately 40 minutes to complete each experimental session for each participant for Phase I. The total VDV for all the stimulus pairs used in this part of the trial was $10.6 \mathrm{~ms}^{-1.75}$.

Following the completion of Phase I, the participants attended the laboratory for Phase II of the study. During this Phase, the participants attended the laboratory for two 
sessions. The first session comprised calibration and familiarisation, during which the participants were exposed to the $8 \mathrm{~Hz}$ stimulus and a dummy run of one of the trials. For the experimental session of Phase II, the participants were exposed to a stimulus comprising a frequency of $8 \mathrm{~Hz}$ at a vibration magnitude of $2 \mathrm{~ms}^{-2}$ r.m.s for three repeats of four pairs of reference-comparator seat positions: $45^{\circ} \& 0^{\circ}, 45^{\circ} \& 22.5^{\circ}, 45^{\circ}$ \& $67.5^{\circ}$, and $45^{\circ} \& 90^{\circ}$. A similar test protocol was used for Phase I and Phase II.

It took approximately 40 minutes to complete each experimental session for each participant for Phase II. The total VDV for all the stimulus pairs used in this part of the trial was $11.3 \mathrm{~ms}^{-1.75}$.

\section{Results}

As described above, participants were asked to express their perceived level of discomfort for a given test stimulus with respect to the reference stimulus, using a comparative scale where $100 \%$ represented the two stimuli being equal. As no upper bounds or resolution were set, participants were free to map their subjective impression of the whole-body vibration to the objective scale in any way that they felt appropriate. For example, one participant used the range from $80 \%$ to $140 \%$ and another subject used the range from 50\% to 500\%. The results from Phase I are summarised in Figure 3: the graphs show the median of six repeats for each participant (three repeats with a $2 \mathrm{~Hz}$ reference and three repeats with a $16 \mathrm{~Hz}$ reference). Each graph represents one participant's response to each of the five backrest angles, and the differing ranges used by the participants can be clearly seen.

Figure 3 about here 
To directly compare the results from all participants could produce misleading results due to differences between their subjective mapping, and therefore all of the results were normalised using Equation (1) (Mansfield et al., 2000). The normalised results for each participant have zero mean and unity standard deviation, enabling a direct comparison to be made of the relative ratings. Higher values indicate greater ratings of discomfort.

$$
R_{N}=\frac{R_{R}-\bar{X}_{P}}{\sigma_{P}}
$$

Where

$$
\begin{aligned}
& R_{N}=\text { Normalised Score } \\
& R_{R}=\text { Raw Score } \\
& \bar{x}_{P}=\text { Mean of participant's raw scores } \\
& \sigma_{P}=\text { Standard deviation of participant's raw scores }
\end{aligned}
$$

The results from Phase I are shown in Figure 4, with the normalised response against test stimulus frequency (the second of the pair of frequencies presented to each participant). In this figure, the results for both of the reference frequencies (2 Hz and 16 $\mathrm{Hz}$ ) have been combined for each of the test stimulus frequencies. Participants were most sensitive to whole-body vibration in the 4 to $16 \mathrm{~Hz}$ frequency range. For the $0^{\circ}$, $22.5^{\circ}, 45^{\circ}$ and $67.5^{\circ}$ backrest angles, the greatest ratings occurred at $8 \mathrm{~Hz}$; for the $90^{\circ}$ backrest angle, the greatest ratings occurred at $4 \mathrm{~Hz}$.

Figure 4 about here 
The normalised results from Phase II are shown in Figure 5. During Phase II, the stimulus frequency was kept constant at $8 \mathrm{~Hz}$ and the backrest angle varied. A backrest angle of $45^{\circ}$ was chosen as the reference position and therefore has a value of zero in Figure 5. At $8 \mathrm{~Hz}$ (the frequency where participants were most sensitive to vibration), the recumbent position of $0^{\circ}$ was considered to be the most uncomfortable and the backrest angle of $67.5^{\circ}$ was the least uncomfortable. Generally the effect of backrest angle on perceived comfort at $8 \mathrm{~Hz}$ was significant $(p<0.05$, paired-samples t-test; Table 1). The only exceptions occurred for comparison of results obtained at $22.5^{\circ}$ and $90^{\circ}$ and results obtained at $45^{\circ}$ and $90^{\circ}$. For each of the practical backrest angle transitions $\left(0^{\circ} \leftrightarrow 22.5^{\circ}, 22.5^{\circ} \leftrightarrow 45^{\circ}, 45^{\circ} \leftrightarrow 67.5^{\circ}\right.$ and $\left.67.5^{\circ} \leftrightarrow 90^{\circ}\right)$ significant differences were observed.

Figure 5 about here

\section{Table 1 about here}

If Figure 4 was to be plotted on a 3-dimensional graph ( $x$-axis = frequency, $y$ axis $=$ backrest angle, $z$-axis = normalised perceived discomfort), then Figure 5 would be a perpendicular slice through the frequency axis at $8 \mathrm{~Hz}$. The result of normalising the values of the results of Phase I at $8 \mathrm{~Hz}$ (Figure 4) according to the results from Phase II (Figure 5) is shown in Figure 6, which describes the relationship between backrest angle and perceived comfort. These combined results show that the extreme postures $\left(0^{\circ}\right.$ and $\left.90^{\circ}\right)$ were the most uncomfortable. 


\section{Weighting Filters}

\subsection{Weighting filters defined by ISO 2631-1 and BS 6841}

Both ISO 2631-1 (1997) and BS 6841 (1987) describe methods of calculating vibration exposure from acceleration data. The two standards differ in the calculations used (Griffin, 1998; Rimell and Mansfield, 2007), but both have similar methods of weighting the data prior to calculation. This paper only considers vertical vibration, and therefore horizontal or rotational vibration, and the application of the standards to upright standing operators will not be considered.

The standards provide frequency weighting curves dependent on the posture of the operator, the direction of the vibration, and whether the measurement is required for an indication of health risk, comfort, perception threshold or motion sickness. For operators using a recumbent or upright sitting posture and for vertical motion, ISO 2631-1 (1997) recommends the use of its Wk curve and BS 6481 (1987) recommends the use of its Wb curve. These two curves are shown in Figure 7, and it can be seen that there are slight differences in the magnitude response, although they have similar general shapes (Mansfield, 2005).

Figure 7 about here

The frequency weighting curves are defined by a set of s-domain (Laplace operator) equations and by tabulated third-octave values. ISO 2631-1 weighting curves are defined by the following equations: 
High-pass

$$
H_{h}(s)=\frac{s^{2}}{s^{2}+\frac{\omega_{1}}{Q_{1}} s+\omega_{1}^{2}}
$$

Low-pass

$$
H_{l}(s)=\frac{\omega_{2}{ }^{2}}{s^{2}+\frac{\omega_{2}}{Q_{2}} s+\omega_{2}{ }^{2}}
$$

Accel-vel transition $H_{t}(s)=\frac{\left(Q_{4} \cdot \omega_{4}{ }^{2}\right) s+\left(Q_{4} \cdot \omega_{4}{ }^{2} \cdot \omega_{3}\right)}{\left(Q_{4} \cdot \omega_{3}\right) s^{2}+\left(\omega_{3} \cdot \omega_{4}\right) s+\left(Q_{4} \cdot \omega_{4}{ }^{2} \cdot \omega_{3}\right)}$

Step

$$
H_{s}(s)=\frac{s^{2}+\frac{\omega_{5}}{Q_{5}} s+\omega_{5}{ }^{2}}{s^{2}+\frac{\omega_{6}}{Q_{6}} s+\omega_{6}{ }^{2}}
$$

where: $\omega_{n}=2 \pi f_{n}$ and $f_{n}=$ corner frequency

The total weighting function is defined as:

$$
H_{\text {ISO }}(s)=G \cdot H_{h}(s) \cdot H_{l}(s) \cdot H_{t}(s) \cdot H_{s}(s)
$$

where $G$ is a scalar gain value.

The coefficient values for Wk are given in Table 2 . By replacing $s$ with j $\omega$, and then separating the real and imaginary parts, the complex frequency response can be obtained. The magnitude and phase response can be obtained by use of a rectangular-topolar conversion. 
The BS 6841 weighting curves for $\mathrm{Wb}$ are defined by the following equations:

Band-limiting $\quad H_{b}(s)=\frac{s^{2}}{s^{2}+\frac{\omega_{1}}{Q_{1}} s+\omega_{1}{ }^{2}} \cdot \frac{\omega_{2}{ }^{2}}{s^{2}+\frac{\omega_{2}}{Q_{1}} s+\omega_{2}{ }^{2}}$
Weighting $\quad H_{w}(s)=\frac{s^{2}+\frac{\omega_{5}}{Q_{3}} s+\omega_{5}{ }^{2}}{s^{2}+\frac{\omega_{6}}{Q_{4}} s+\omega_{6}{ }^{2}} \cdot \frac{s+\omega_{3}}{s^{2}+\frac{\omega_{4}}{Q_{2}} s+\omega_{4}{ }^{2}} \cdot \frac{2 \pi K f_{4}{ }^{2} f_{6}{ }^{2}}{f_{3} f_{5}{ }^{2}}$

where: $\omega_{n}=2 \pi f_{n}$ and $f_{n}=$ corner frequency

The total weighting function is defined as:

$$
H_{B S}(s)=H_{b}(s) \cdot H_{w}(s)
$$

It can be shown that Equation 6 is algebraically equivalent to Equation 9 when the substitutions shown in Table 3 are used and when Q1 = Q2. Therefore, the weighting filters described in Table 2 can also be implemented using the $s$-domain equations of BS 6841 (Equation 7 to Equation 9).

Table 3 about here

Rimell and Mansfield (2007) have proposed a general method for implementing vibration weighting filters as infinite impulse response (IIR) filters for inclusion in analysis software, the methods presented are applicable to the filters described here. 
Alternatively, the filters can be converted to linear-phase finite impulse response (FIR) digital filters as described by Notini and Mansfield (2004).

\subsection{Weighting filter design for a wide range of postures}

Using the s-domain equations for Wk (Equation 2 to Equation 6), the parameters were selected such that the calculated transfer function was an optimum fit with the measured data. A minimum least-squares metric was used to fit the data. Figure 8 shows an example where the measured data points and the transfer function are shown for the $90^{\circ}$ posture. As the experimental data only covered the frequency range from $2 \mathrm{~Hz}$ to $64 \mathrm{~Hz}$, the response outside of this range is unknown and therefore the new filters include lowand high-pass filtering to limit the influence of the out-of-band frequencies (a similar band-limiting function is also included in the current standards). The complete set of weighting filters is shown in Figure 9 and their coefficients are presented in Table 2. These filters may be implemented by inserting the coefficients into Equations 2 to 6 or into an existing digital implementation.

Figure 8 about here

Figure 9 about here

The experiment, and hence the resulting weighting filters, are defined only at discrete backrest angles; however, through the use of an interpolation strategy, it is possible to calculate a weighting filter for any angle between $0^{\circ}$ (recumbent) and $90^{\circ}$ (upright). The interpolation enables any weighting filter coefficients to be calculated for any backrest angle and is based on a 4th order polynomial fit of the form: 


$$
y=\sum_{j=0}^{4} a_{j} \cdot x^{j}
$$

where $a$ is the coefficient and $x$ is the backrest angle. The coefficients shown in Table 4 were calculated using a Singular Value Decomposition (SVD) polynomialfitting algorithm, and the correlation coefficient, $r$, is equal to unity for every one of interpolated filter coefficients. Because $r=1$, the interpolated frequency responses are an exact match to those found experimentally for the backrest angles of $0^{\circ}, 22.5^{\circ}, 45^{\circ}$, $67.5^{\circ}$ and $90^{\circ}$. For example, consider the equation for $f_{5}$ as a function of backrest angle, $x:$

$$
f_{5}=3.13+0.608 x-0.022176 x^{2}+3.4283 \times 10^{-4} x^{3}-1.9054 \times 10^{-6} x^{4}
$$

It is advisable to exercise caution when interpolating between $90^{\circ}$ and $67.5^{\circ}$, as the response between these angles is uncertain. Figure 10 shows the interpolated filter for a backrest angle of $10^{\circ}$, and also the two nearest filters based on the experimental results for $0^{\circ}$ and $22.5^{\circ}$.

Table 4 about here

Figure 10 about here

\section{Discussion}

The aim of this study was to investigate whether seat backrest angle influenced perceived comfort during vertical whole-body vibration. This study has showed that, in 
general, the level of perceived discomfort increases with decreasing backrest angle (i.e. more reclined). At $8 \mathrm{~Hz}$ (the frequency of most sensitivity in this study) it was monotonic from $67.5^{\circ}$ to $0^{\circ}$. Also noteworthy is that the participants are most sensitive to whole-body vibration over the frequency range of $4 \mathrm{~Hz}$ to $8 \mathrm{~Hz}$, which corresponds to the region of the resonance frequency of the human body (Mansfield et al., 2000; Paddan and Griffin, 1988).

Previous research into biomechanics of humans on stationary chairs (Magnusson et al., 1994; Magnusson and Pope, 1998; Goel et al., 1999; Kayis and Hoang, 1999; Wilke et al., 1999; Lengsfeld et al., 2000) has shown that chairs with armrests, a tilting seat-pan and a lumbar support reduce intradiscal pressure in the spine, and also that intradiscal pressure decreases as the backrest angle decreases (becomes more recumbent). A decrease in spinal intradiscal pressure results in a reduction in the perceived discomfort of the user. The research, which only considered a limited range of postures with backrest angles from $-10^{\circ}$ (anterior lean) to $50^{\circ}$ (posterior lean) and recumbent, also recommended a backrest angle of $70^{\circ}$. The findings from the experiment described in this paper suggest that such earlier research may also be applicable to chairs mounted to vibrating surfaces for backrest angles of between $90^{\circ}$ and $45^{\circ}$.

The upright $90^{\circ}$ posture is considered to be the most uncomfortable at all frequencies except $8 \mathrm{~Hz}$, which is to be expected as, for postural support, a reclined sitting position is desirable for maximum comfort, allowing the muscles to relax. It is also possible that, in the $90^{\circ}$ position, the back was not pressed hard against the backrest, effectively resulting in an unsupported back, which, according to Nachemson (1985), applies about twice the intradiscal pressure to the spine compared with the relaxed sitting position. The recommended backrest angle for an office chair is $70^{\circ}$ to 
$75^{\circ}$, with a seat-pan tilt of $5^{\circ}$ to $10^{\circ}$ (Pheasant, 1990). The $67.5^{\circ}$ and $45^{\circ}$ postures produced less discomfort than the $90^{\circ}$ posture whilst exposed to vibration at all frequencies investigated in this study. In this experiment, participants' hands were by their sides. If, however, the participants were engaged in a task where their arms were above shoulder height, it is expected that they would find the recumbent positions increasingly uncomfortable after a short period of time (Magnusson and Pope, 1998).

Figures 11 and 12 compare the results from this study with the results published by Maeda et al., (2001). The posture used in the experiment described in this paper for the recumbent $\left(0^{\circ}\right)$ position is slightly different (the legs were bent to represent a possible driving position) to that used in the experiment reported by Maeda. The disparity in the curves at higher frequencies (see Figure 11) may be due to the use of different head supports (this experiment used a padded head-rest whereas Maeda used no head support). ISO 2631-1 suggests the use of Wj frequency weighting for supine vibration exposures without padded head support; this shows greater sensitivity to high frequency vibration, similar to the results reported by Maeda. The posture for the upright position $\left(90^{\circ}\right)$ in this experiment corresponded to that used by Maeda and the measured response below $16 \mathrm{~Hz}$ is very similar to the results published by Maeda (see Figure 12).

Figure 11 about here

Figure 12 about here

If it is required to control risk from whole-body vibration, then the new set of frequency weighting filters presented here could be used to augment assessments 
according to ISO 2631-1. The standard format enables users to apply the filters using their existing filter topologies (either analogue or digital) simply by inserting the new coefficient values. In most cases this would result in backrest angles of $67.5^{\circ}$ being shown to be preferable, and fully reclined to be worst. Other ergonomic considerations, such as static postural loading and fatigue, should also be considered.

\section{References}

BRITISH STANDARDS INSTITUTION 1987, Measurement and evaluation of human response to whole-body mechanical vibration and repeated shock, BS 6841 London: British Standards Institution.

BOVENZI, M. and BETTA, A. 1994, Low-back disorders in agricultural tractor drivers exposed to whole-body vibration and postural stress, Applied Ergonomics, 25, 231-241.

BOVENZI, M. and HULSHOF, C.T.J. 1998, An updated review of epidemiologic studies on the relationship between exposure to whole-body vibration and low back pain, Journal of Sound and Vibration, 214(4), 595-612.

BOVENZI, M. and ZADINI, A. 1992, Self-reported lower back symptoms in urban bus drivers exposed to whole-body vibration, Spine, 17, 1048-1059.

CORBRIDGE, C., GRIFFIN, M.J. and HARBOROUGH, P. 1989, Seat dynamics and passenger comfort, Institute of Mechanical Engineers, Part F: Journal of Rail and Rapid Transit, 203, 57-64.

EDMONDS, J. 1994, The effect of reclined sitting posture on hand controlled operations. Contemporary Ergonomics. Ed. S A Robertson. 138-143. Taylor \& Francis, London.

EDWARDS, R.J., STREETS, D.F. and BOND, G. 1994, The effects of back angle inclination on target detection, Proceedings of the Human Factors and Ergonomics Society 38th Annual Meeting 2, 1252-1255.

EUROPEAN COMMISSION 2002, Directive 2002/44/EC of the European Parliament and of the Council of 25 June 2002 on the minimum health and safety 
requirements regarding exposure of workers to the risks arising from physical agents (vibration). Official Journal of the European Communities, L177. 13-19.

GOEL, V.K., MONTGOMERY, R.E., GROSLAND, N.M., POPE, M.H. and KUMAR, S. 1999, Biomechanics in ergonomics, (Taylor \& Francis), Chapter 14.

GRIFFIN, M.J. 1998, A comparison of standardized methods for predicting the hazards of whole-body vibration and repeated shocks, Journal of Sound and Vibration, 215, 883-914.

GRIFFIN, M.J., LEWIS, C.H., PARSONS, K.C. and WHITHAM, E.M. 1979, The biomechanical response of the human body and its application to standards. AGARD Conference Proceedings CP253, Models and Analogues for the Evaluation of Human of Human Biomechanical Response, Performance and Protection, Paris 6-10 November 1978 (Von Gierke, H.E., ed.) Paper A28. Advisory Group on Aerospace Research and Development.

GRIFFIN, M.J., WHITHAM, E.M. and PARSONS, K.C. 1982, Vibration and Comfort. 1. Translational seat vibration, Ergonomics, 25, 721-739.

GUIGNARD, J.C. 1985, Vibration. In: Patty’s Industrial Hygiene and Toxicology, Vol 3b: Biological Responses, 2nd Edition (Cralley and Cralley, eds), 635-724, New York, Wiley.

INTERNATIONAL ORGANISATION FOR STANDARDISATION 1997, Mechanical vibration and shock-Evaluation of human exposure to whole-body vibration - Part 1: General requirements, ISO 2631-1.

KAYIS, B. and HOANG, K. 1999, Static three-dimensional modelling of prolonged seat posture, Applied Ergonomics, 30, 255-262.

LENGSFELD, M., FRANK, A., DEURSEN, D.L.V. and GRISS, P. 2000, Lumbar spine curvature during office chair sitting, Medical Engineering and Physics, 22, 665-669.

MAEDA, S., YONEKAWA, Y., OKAMOTO, N., HIRAO, Y. and YOKOTA, A. 2001, Whole-body vibration perception thresholds with different postures. Presented at Internoise 2001, The Hague, The Netherlands. 
MAGID, E.B., COERMANN, R.R. and ZIEGENRUECKER, G.H. 1960, Human tolerance to whole-body sinusoidal vibration: short-time, one minute and three minute studies, Aerospace Medicine, 31, 915-924.

MAGNUSSON, M., HANSSON, T. and POPE, M.H. 1994, The effect of seat back inclination on spine height changes, Applied Ergonomics, 25 (5), 294-298.

MAGNUSSON, M.L. and POPE, M.H. 1998, A review of the biomechanics and epidemiology of working postures (it isn’t always vibration which is to blame!), Journal of Sound and Vibration, 215(4), 965-976.

MANSFIELD, N.J. 2005, Human Response to Vibration. Boca Raton, FL: CRC Press.

MANSFIELD, N.J. and MARSHALL, J.M. 2001, Symptoms of musculoskeletal disorders in stage rally drivers and co-drivers, British Journal of Sports Medicine, 35, 314-320.

MANSFIELD, N.J., HOLMLUND, P. and LUNDSTROM, R. 2000, Comparison of participative responses to vibration and shock with standard analysis methods and absorbed power, Journal of Sound and Vibration, (3), 477-491.

MEHTA, C.R. and TEWARI, V.K. 2000, Seating discomfort for tractor operators - a critical review, International Journal of Industrial Ergonomics, 25, 661-674.

NACHEMSON, A. 1985, The lumbar spine and back pain. Pitman. Chap. 12.

NOTINI, L. and MANSFIELD, N.J. 2004, Evaluation of digital implementations of whole-body vibration frequency weighting filters and the effect of filter phase response on whole-body vibration metrics. Proceedings of the 39th UK Group Conference on Human Response to Vibration, Ludlow, UK, September 2004.

OZKAYA, N., GOLDSHEYDER, D. and WILLEMS, B. 1996, Effect of operator seat design on vibration exposure, American Industrial Hygiene Association Journal, 57, 837-842.

PADDAN, G.S. and GRIFFIN, M.J. 1988, The transmission of translational seat vibration to the head. I. Vertical seat vibration, Journal of Biomechanics, 21, 191197.

PADDAN, G.S., HOLMES, S.R., MANSFIELD, N.J., HUTCHINSON, H., ARROWSMITH, C.I., KING, S.K., JONES, R.J.M. and RIMELL, A.N. 2012, 
The influence of seat backrest angle on human performance during whole-body vibration, Ergonomics, 55(1), 115-128.

PHEASANT, S. 1990, Anthropometrics: an introduction. BSI.

RIMELL, A.N. and MANSFIELD, N.J. 2007, Design of digital filters for frequency weightings required for risk assessments of workers exposed to vibration, Industrial Health, 45, 512-519.

STAYNER, R.M. 2001, Whole-body vibration and shock: A literature review. Extension of a study of overtravel of seat suspensions. Health and Safety Executive, Contract Research Report 333. HSE Books, Sudbury, Suffolk, UK. ISBN 0-7176-1810-2.

THODY, M., GREGG, V.H. and EDWARDS, R.H. 1993, Reclined sitting postures: The effect on human performance of a vigilance task. Contemporary Ergonomics. Ed. E.J. Lovesey 38-33 Taylor \& Francis, London.

WILKE, H., NEEF, P., CAIMI, M., HOOGLAND, T. and CLAES, L. 1999, New in vivo measurements of pressures in the intervertebral disc in daily life, Spine, 24(8), 755-762.

ZERLETT, G. 1986, Relationships between whole-body vibration and disorders of the backbone diagnosed on operators of earth-moving machinery. Backache and Back Discomfort. AGARD Conference Proceedings No.378, Paper 2. Advisory Group for Aerospace Research and Development. 


\section{Figures}

Figure 1 . The five postures used in the experiments illustrating the changes in backrest angle (' $0{ }^{\circ}$ supine', ' $90^{\circ}$ upright').

Figure 2. Apparatus used in the experiment, showing the $67.5^{\circ}$ backrest angle condition.

Figure 3. Raw (non-normalised) results from Phase I for each of the twenty participants (one graph for each participant). Each line shows the mean of six repeats at each backrest angle (three repeats with a $2 \mathrm{~Hz}$ reference and three with a $16 \mathrm{~Hz}$ reference).

Figure 4. Effects of vibration frequency on mean normalised discomfort ratings for 20 participants in five postures. Greater ratings correspond to more discomfort $\left(0^{\circ}=\right.$ recumbent, $90^{\circ}=$ upright).

Figure 5. Effects of backrest angle on mean normalised discomfort ratings for 20 participants tested at $8 \mathrm{~Hz}$. Greater ratings correspond to more discomfort. $\left(0^{\circ}=\right.$ recumbent, $90^{\circ}=$ upright). Error bars show \pm 1 Standard Deviation.

Figure 6. Combined effects of backrest angle and frequency of vibration on mean normalised discomfort ratings for 20 participants. Greater ratings correspond to more discomfort. $\left(0^{\circ}=\right.$ recumbent, $90^{\circ}=$ upright $)$.

Figure 7. Published frequency weighting curves: Wk from ISO 2631-1, Wb from BS 6841.

Figure 8. Filter approximation to measured data for $90^{\circ}$ backrest angle. The dots represent the experimental data and the solid line represents the new weighting filter transfer function.

Figure 9. New weighting curves for different backrest angles and the existing ISO 26311 Wk curve.

Figure 10. Interpolated frequency weighting response for a $10^{\circ}$ backrest angle. The responses at $0^{\circ}$ and $22.5^{\circ}$ are also shown for comparison.

Figure 11. Comparison of subject responses from this study with published data for the $0^{\circ}$ posture (recumbent). Data from Maeda et al.'s study have been scaled for clarity.

Figure 12. Comparison of subject responses from this study with published data for the $90^{\circ}$ posture (upright). Data from Maeda et al.'s study have been scaled for clarity. 


\section{Tables}

Table 1. Results from a paired-Samples t-test for Phase II to examine the significance of an effect of backrest angle at a frequency of $8 \mathrm{~Hz}$. Values below 0.05 are considered to be significant.

Table 2. Coefficients for the new frequency weighting curves and for ISO 2631-1 Wk.

Table 3. Equivalence between the BS and ISO s-domain weighting curve definitions.

Table 4. Interpolation coefficients. 


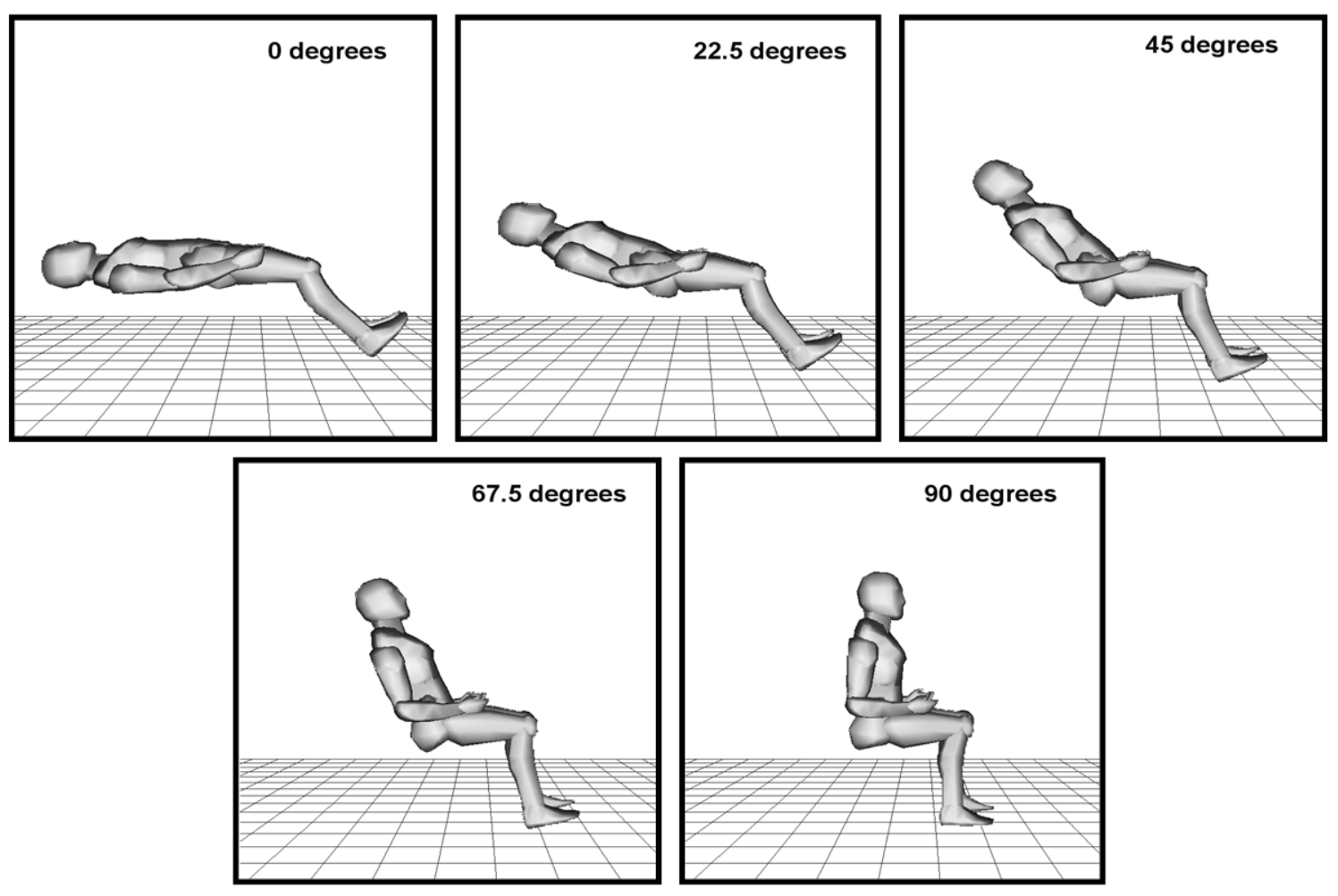

Figure 1 . The five postures used in the experiments illustrating the changes in backrest angle (' $0{ }^{\circ}$ supine', ' $90^{\circ}$ upright'). 


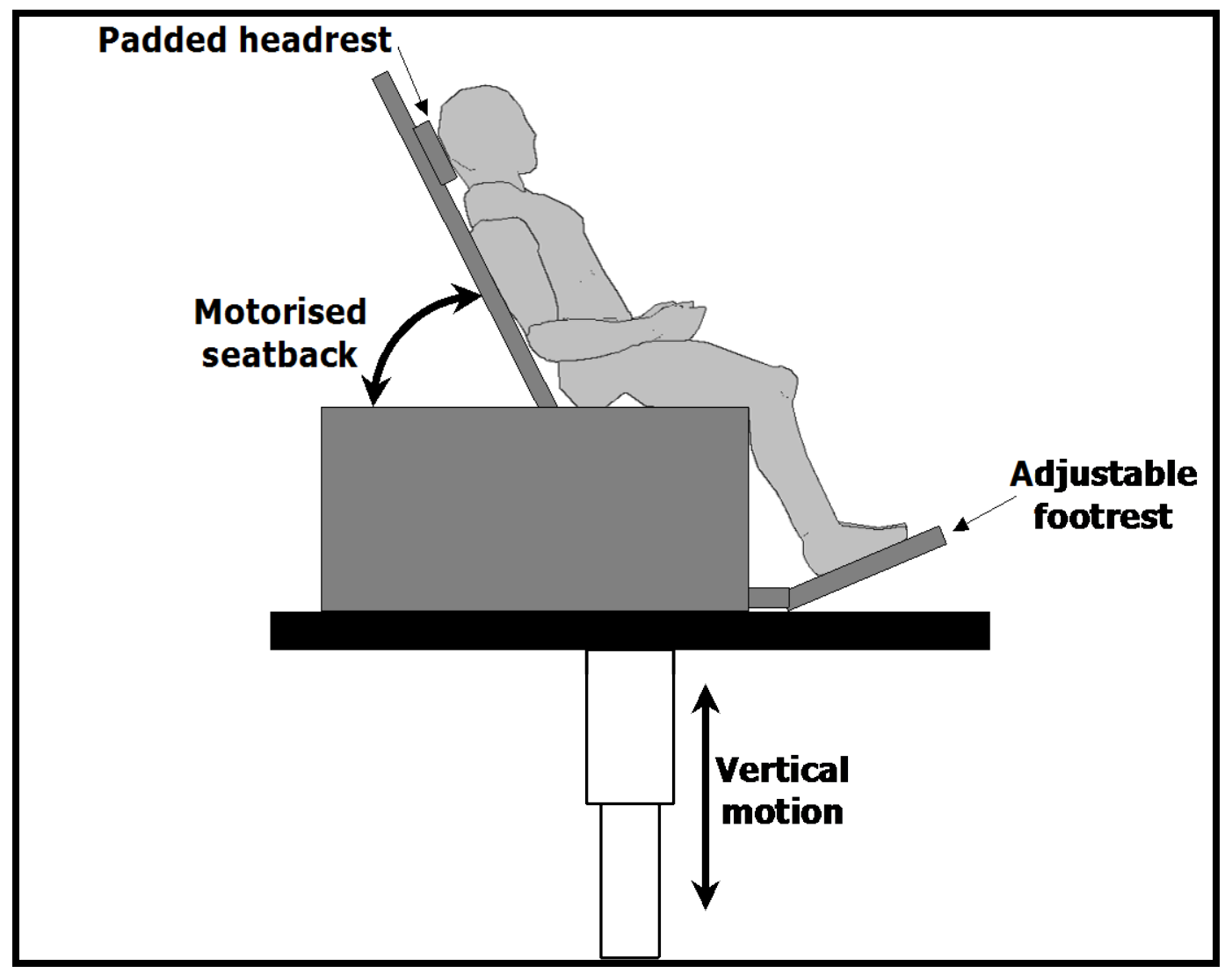

Figure 2. Apparatus used in the experiment, showing the $67.5^{\circ}$ backrest angle condition. 


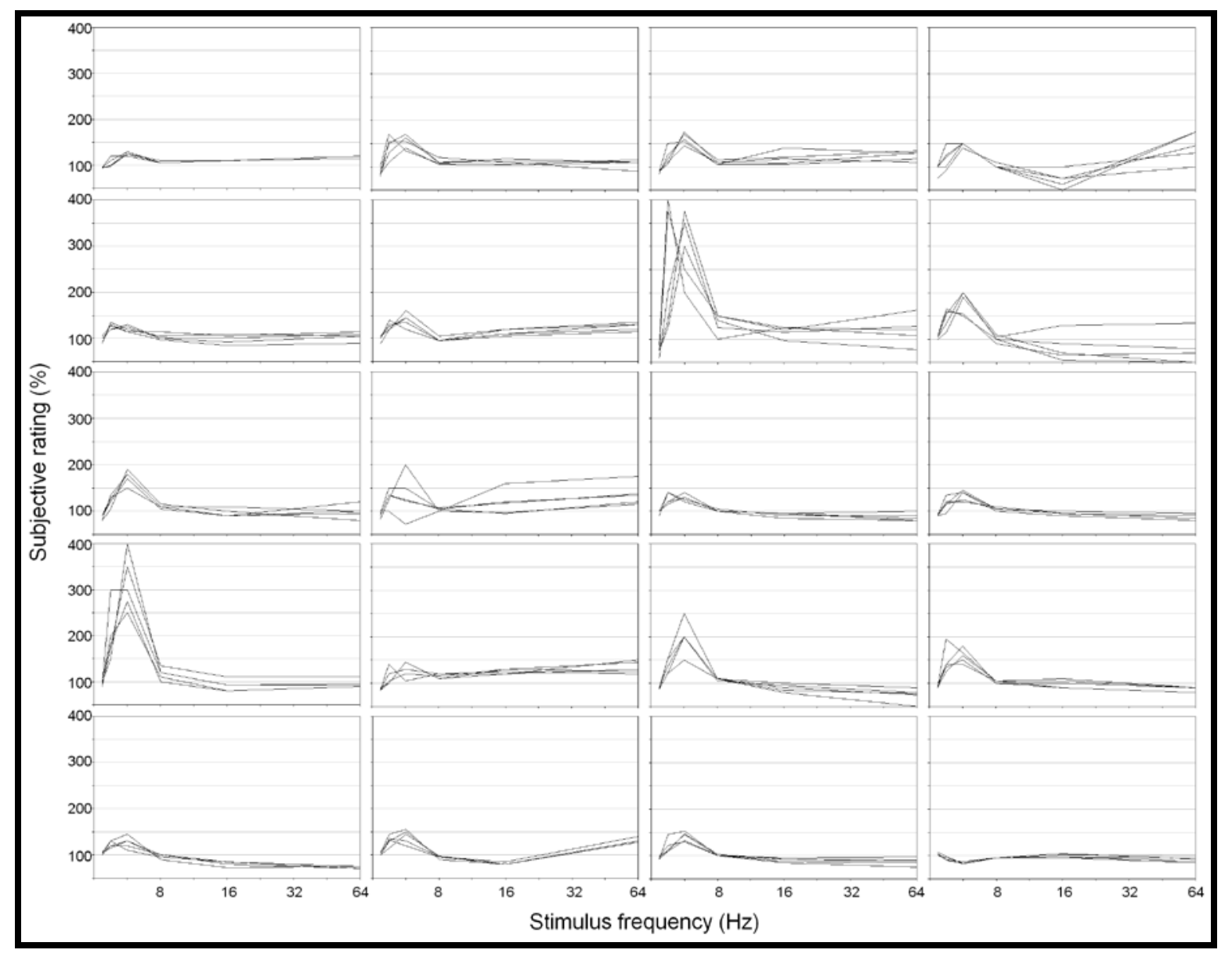

Figure 3. Raw (non-normalised) results from Phase I for each of the twenty participants (one graph for each participant). Each line shows the mean of six repeats at each backrest angle (three repeats with a $2 \mathrm{~Hz}$ reference and three with a $16 \mathrm{~Hz}$ reference). 


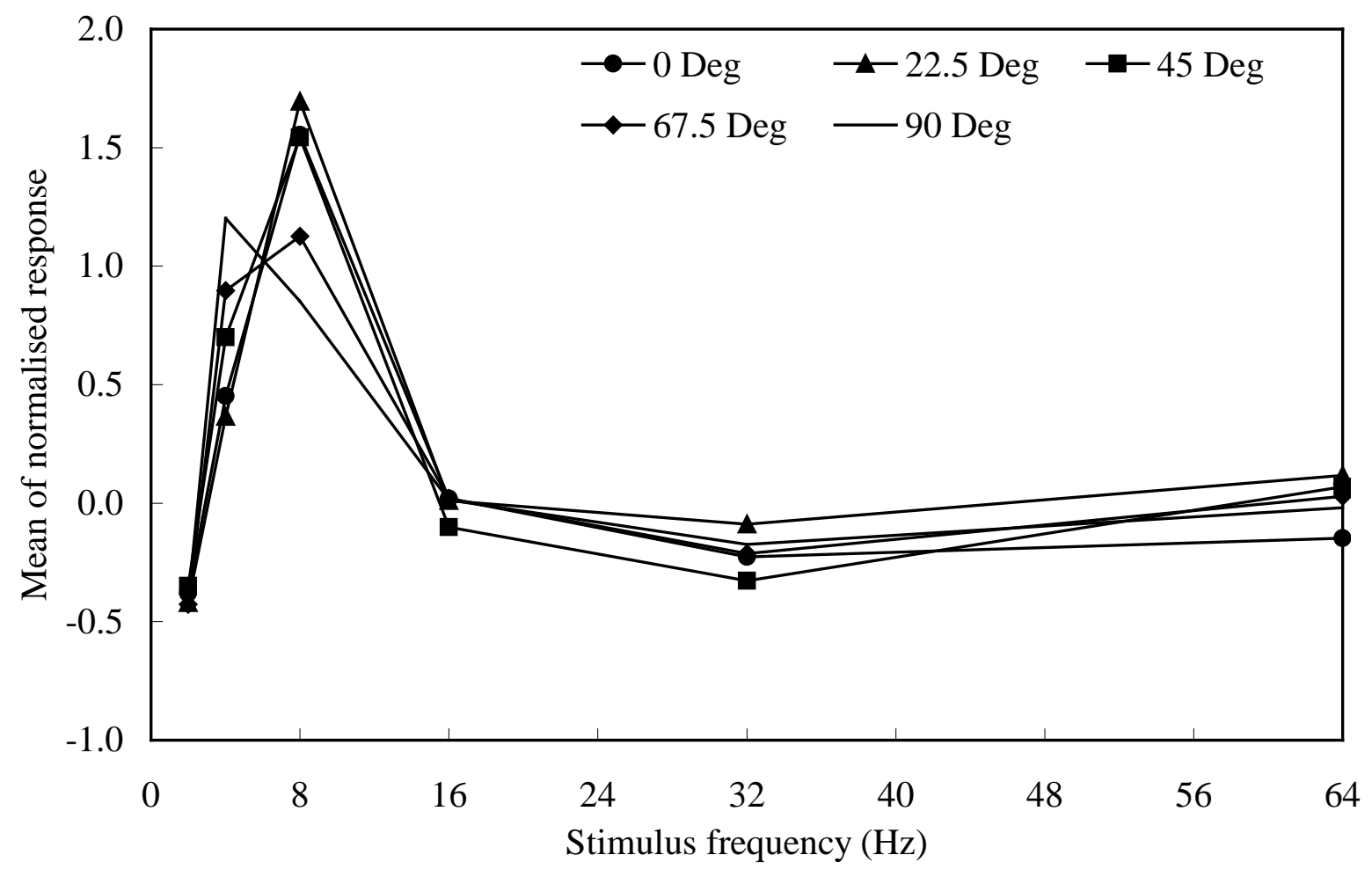

Figure 4. Effects of vibration frequency on mean normalised discomfort ratings for 20 participants in five postures. Greater ratings correspond to more discomfort $\left(0^{\circ}=\right.$ recumbent, $90^{\circ}=$ upright). 


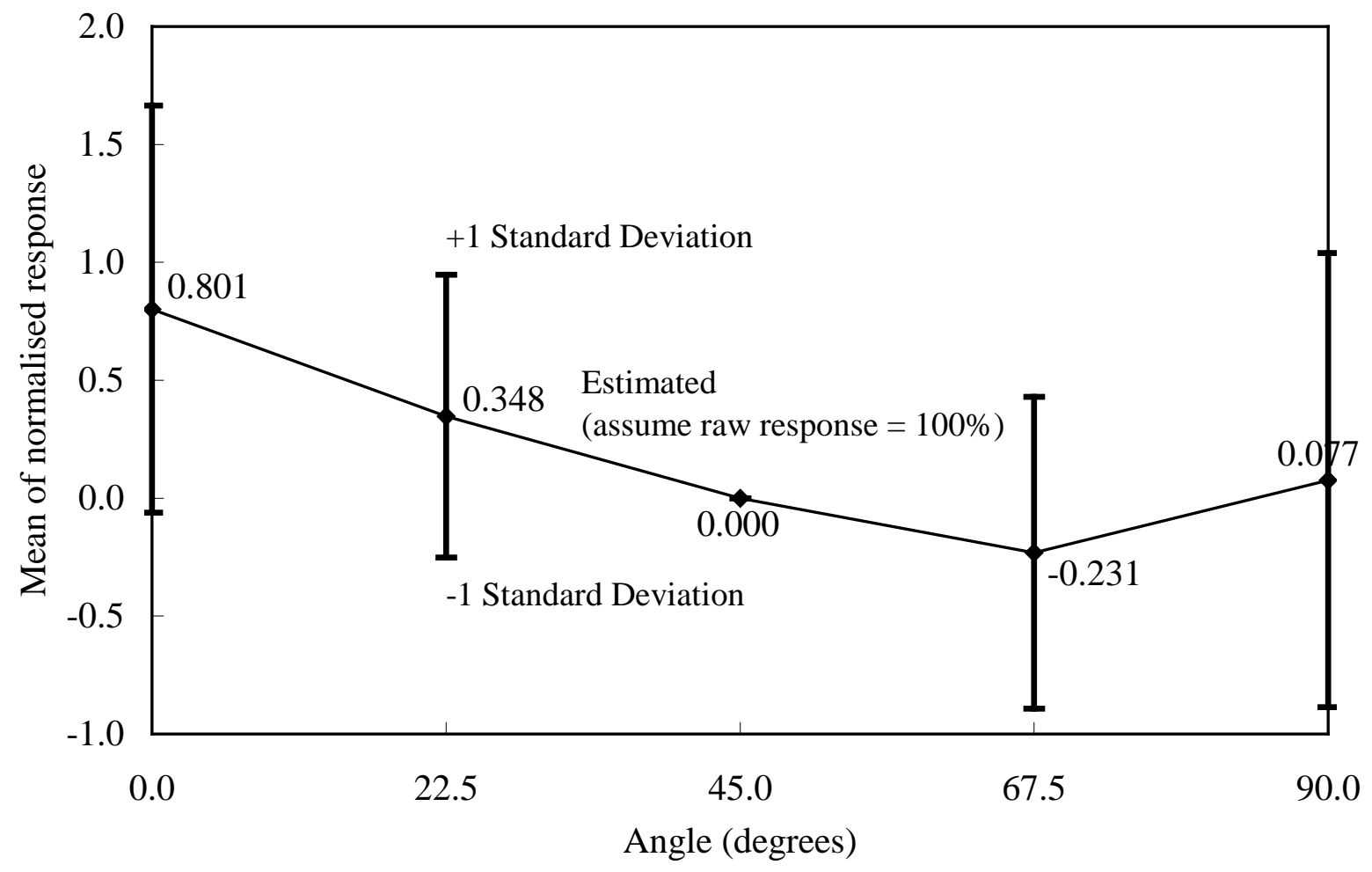

Figure 5. Effects of backrest angle on mean normalised discomfort ratings for 20 participants tested at $8 \mathrm{~Hz}$. Greater ratings correspond to more discomfort. $\left(0^{\circ}=\right.$ recumbent, $90^{\circ}=$ upright). Error bars show \pm 1 Standard Deviation. 


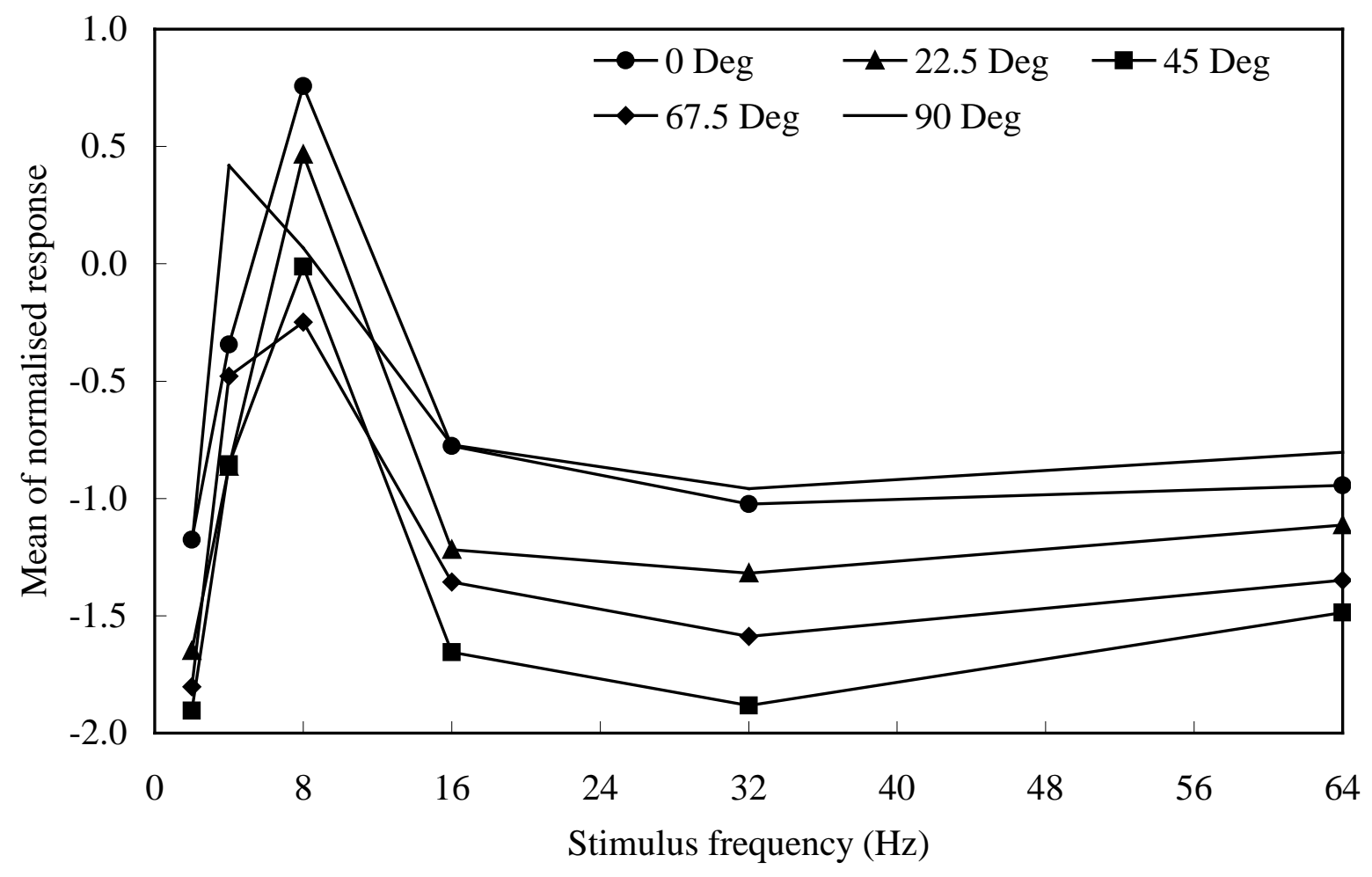

Figure 6. Combined effects of backrest angle and frequency of vibration on mean normalised discomfort ratings for 20 participants. Greater ratings correspond to more discomfort. $\left(0^{\circ}=\right.$ recumbent, $90^{\circ}=$ upright $)$. 


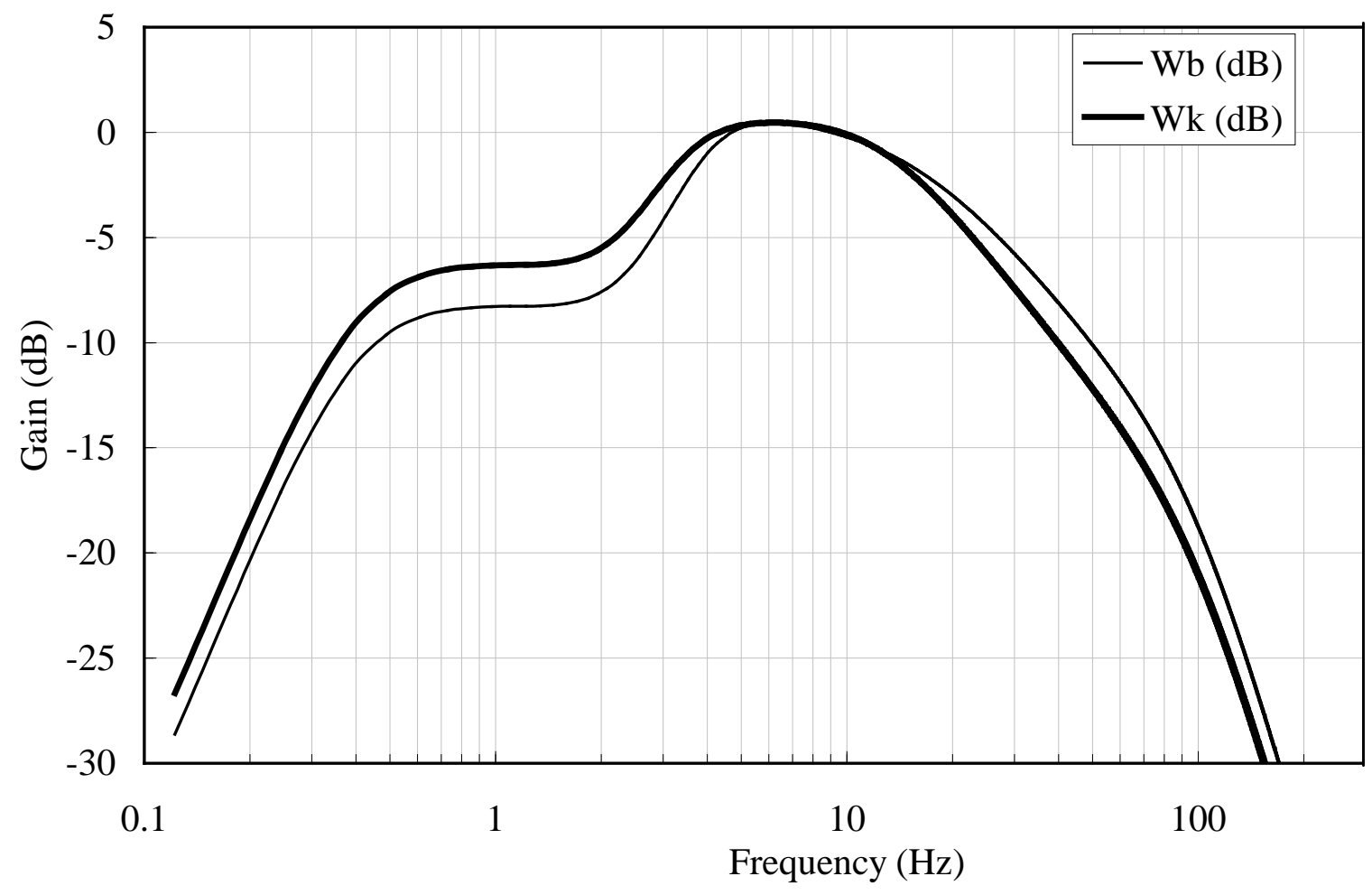

Figure 7. Published frequency weighting curves: Wk from ISO 2631-1, Wb from BS 6841. 


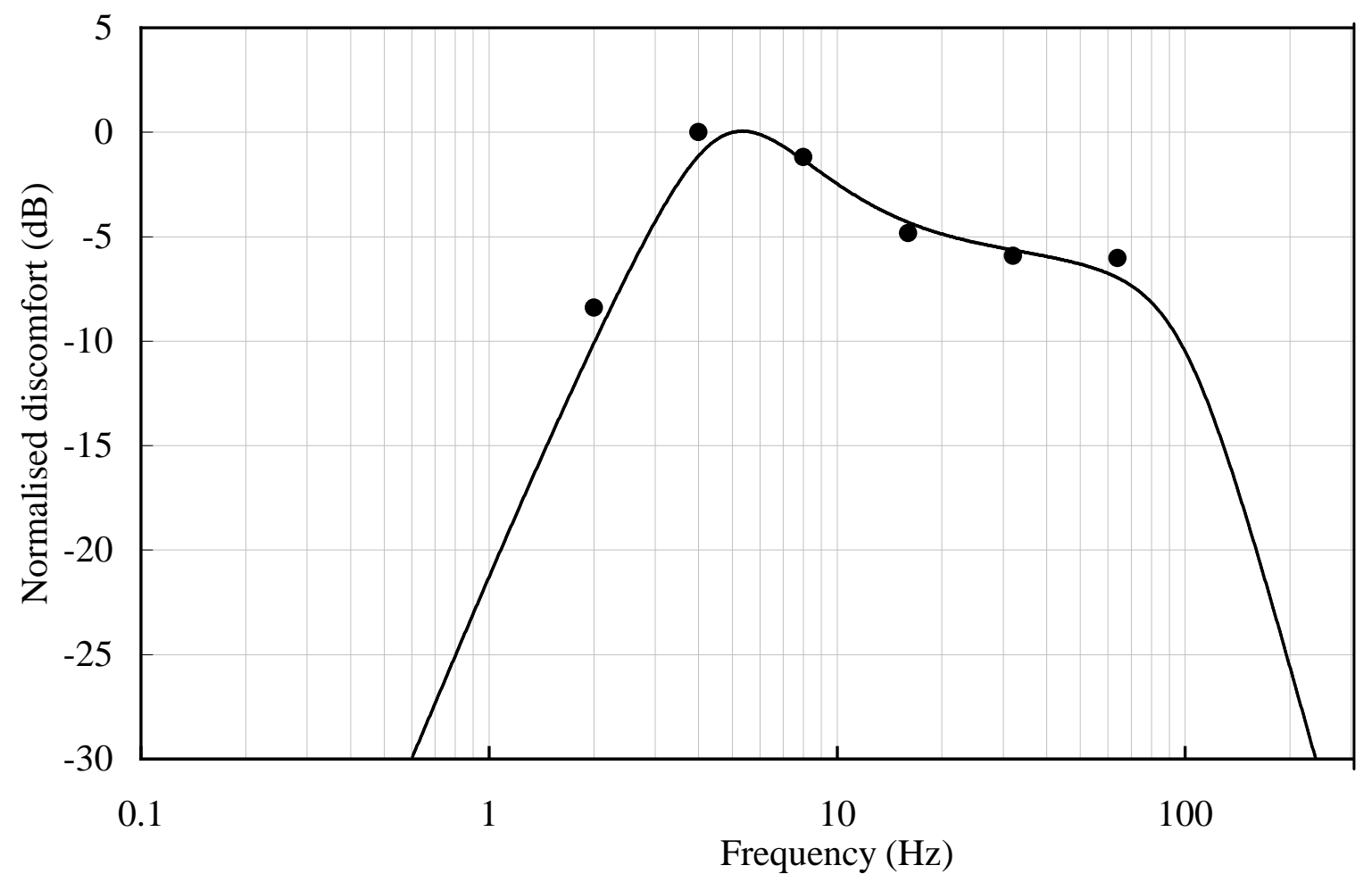

Figure 8. Filter approximation to measured data for $90^{\circ}$ backrest angle. The dots represent the experimental data and the solid line represents the new weighting filter transfer function. 


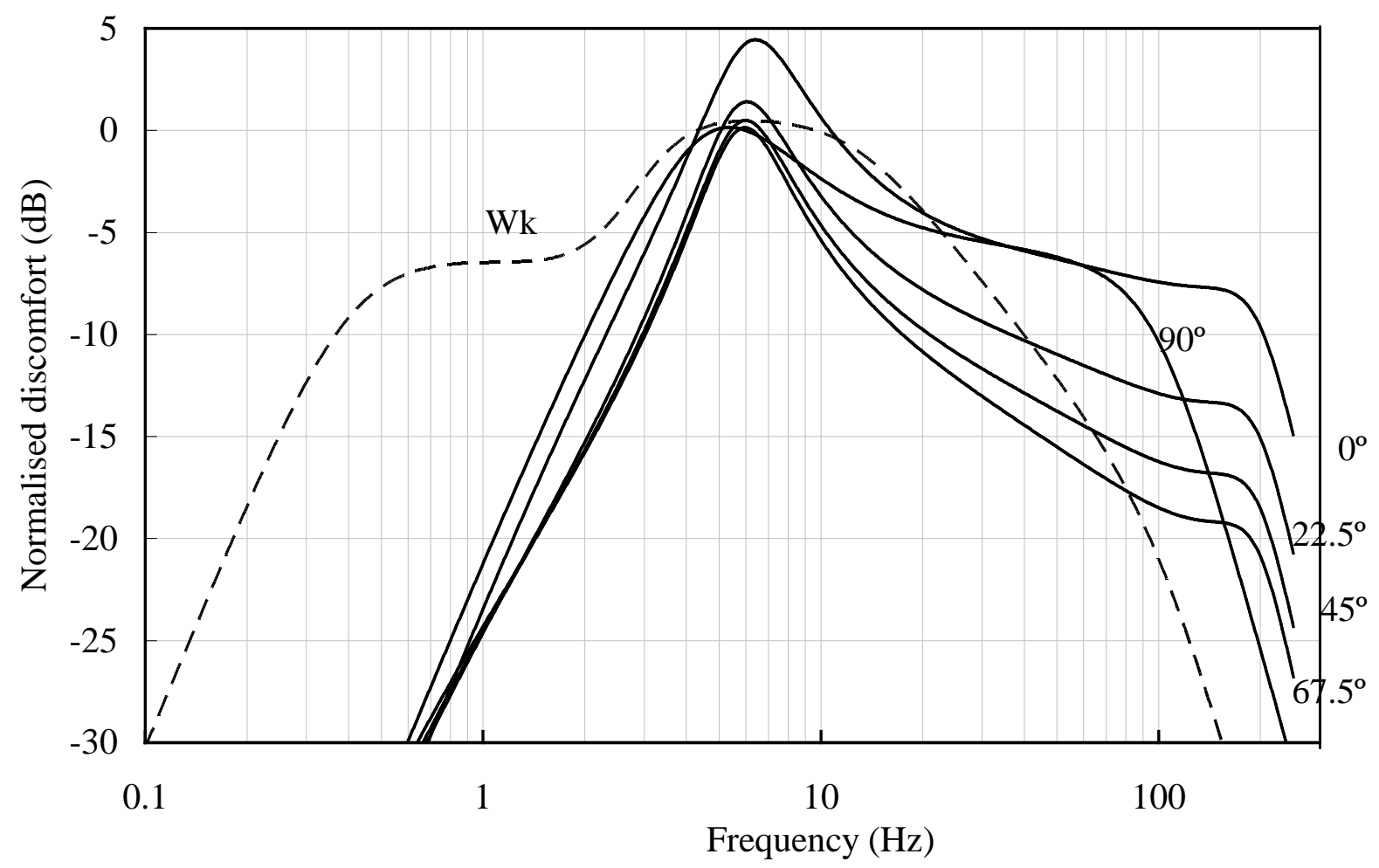

Figure 9. New weighting curves for different backrest angles and the existing ISO 26311 Wk curve. 


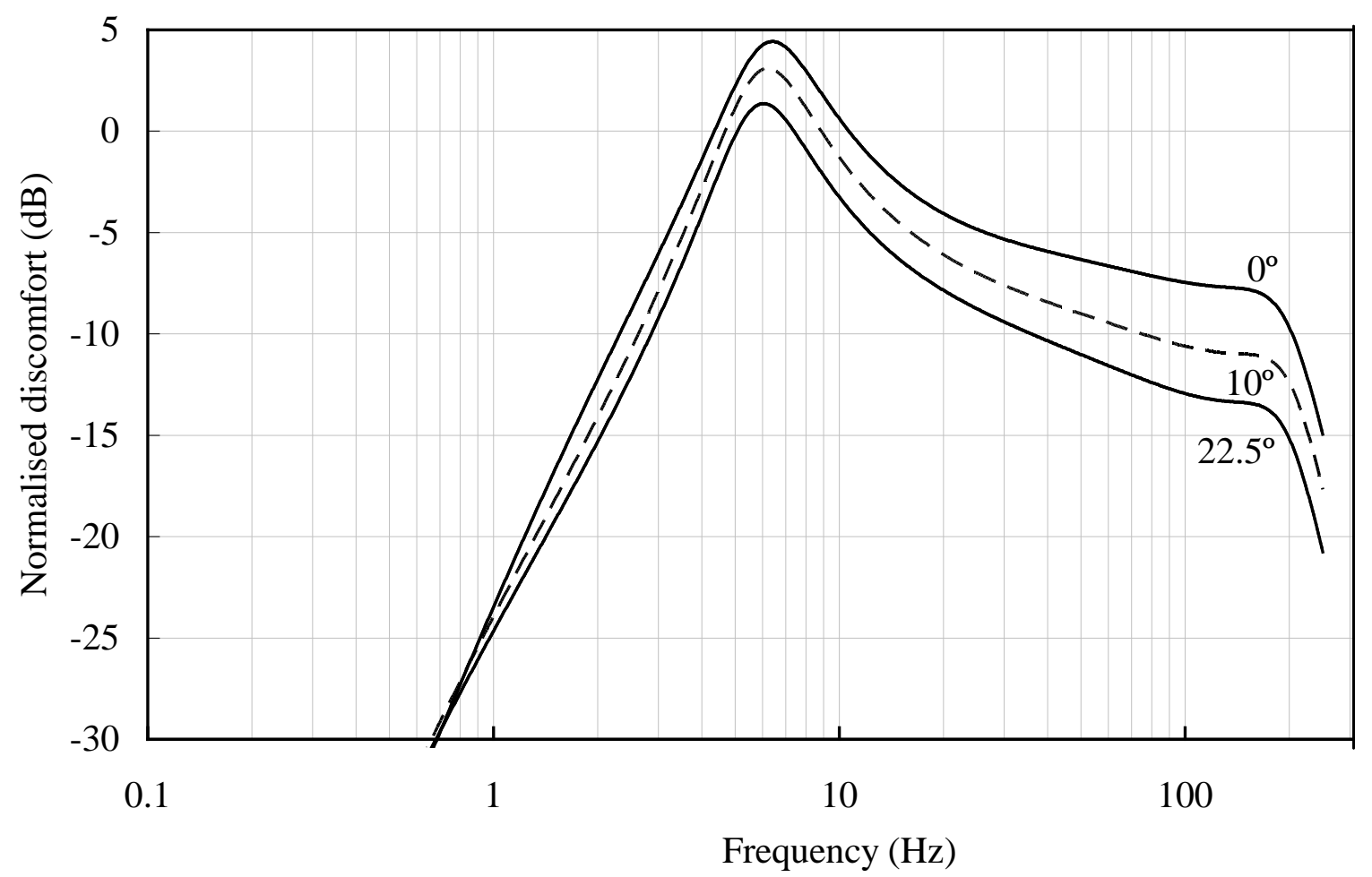

Figure 10. Interpolated frequency weighting response for a $10^{\circ}$ backrest angle. The responses at $0^{\circ}$ and $22.5^{\circ}$ are also shown for comparison. 


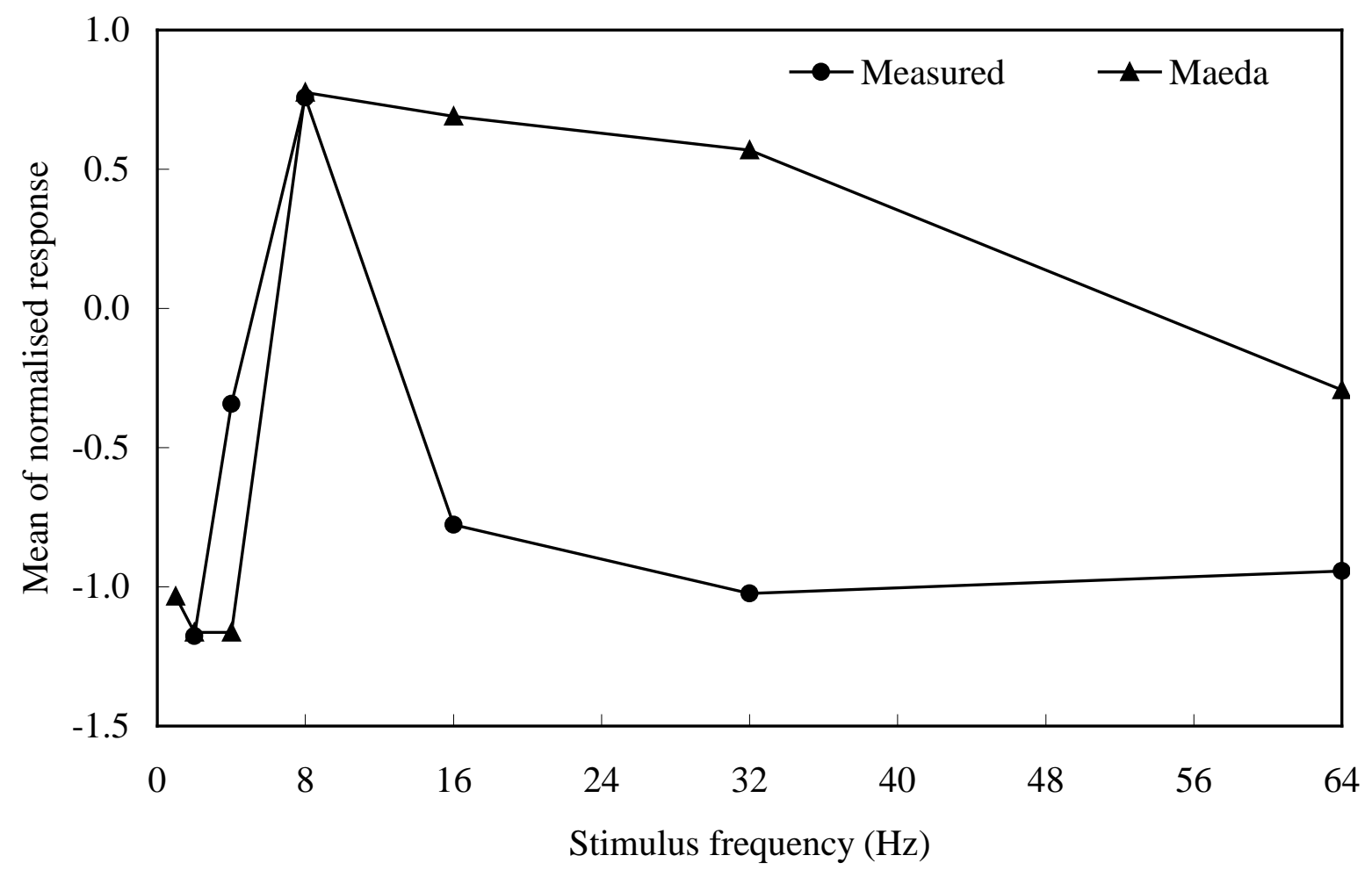

Figure 11. Comparison of subject responses from this study with published data for the $0^{\circ}$ posture (recumbent). Data from Maeda et al.’s study have been scaled for clarity. 


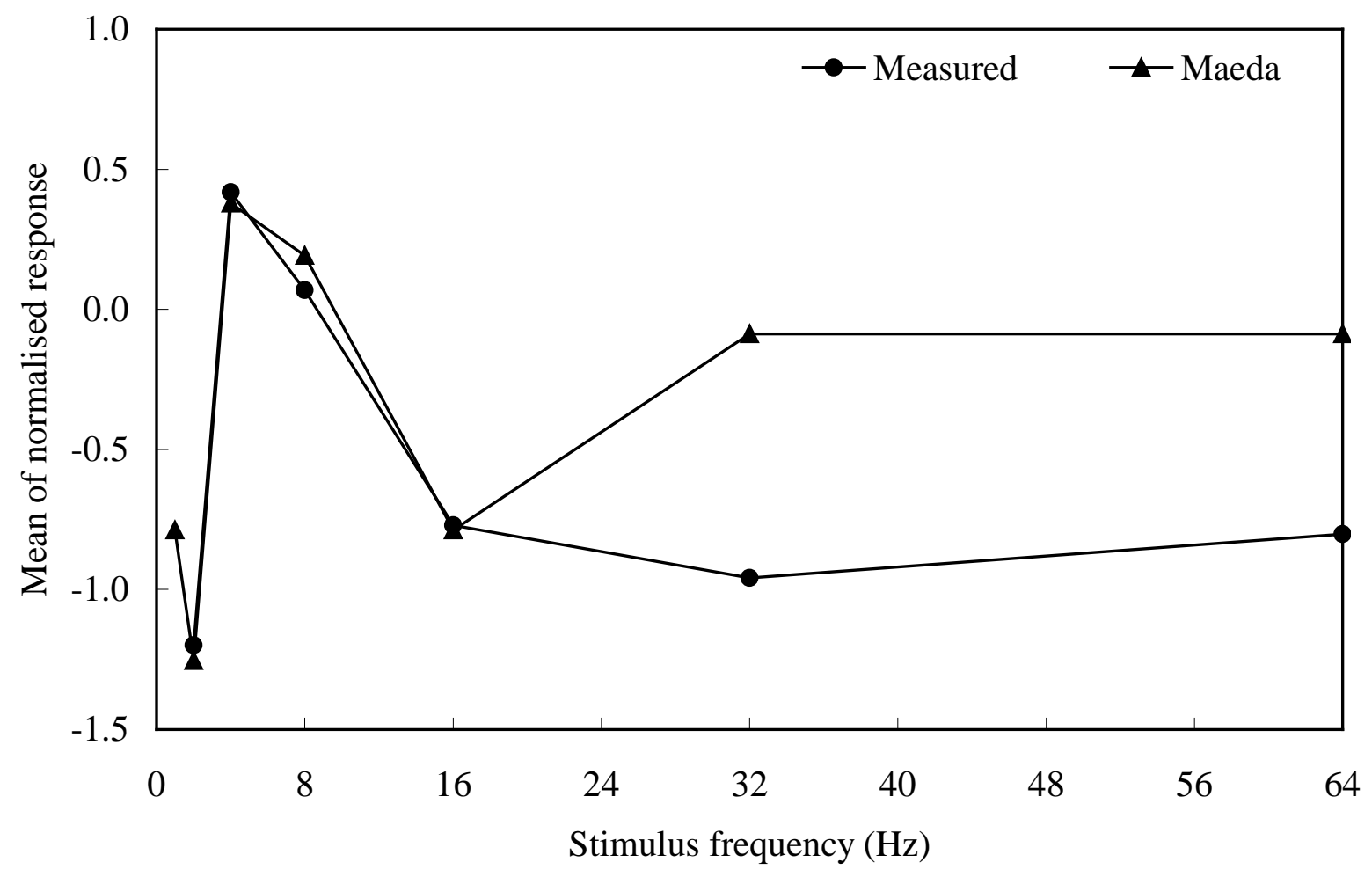

Figure 12. Comparison of subject responses from this study with published data for the $90^{\circ}$ posture (upright). Data from Maeda et al.'s study have been scaled for clarity. 
Table 1. Results from a paired-Samples t-test for Phase II to examine the significance of an effect of backrest angle at a frequency of $8 \mathrm{~Hz}$. Values below 0.05 are considered to be significant.

\begin{tabular}{|c|c|c|c|c|c|c|}
\hline & \multicolumn{5}{|c|}{ Angle } \\
\hline & & $0^{\circ}$ & $22.5^{\circ}$ & $45^{\circ}$ & $67.5^{\circ}$ & $90^{\circ}$ \\
\hline \multirow{5}{*}{ 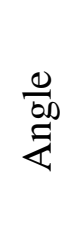 } & $0^{\circ}$ & - & 0.000 & 0.000 & 0.000 & 0.000 \\
\hline & $22.5^{\circ}$ & - & - & 0.001 & 0.000 & 0.127 \\
\hline & $45^{\circ}$ & - & - & - & 0.003 & 0.502 \\
\hline & $67.5^{\circ}$ & - & - & - & - & 0.004 \\
\hline & $90^{\circ}$ & - & - & - & - & - \\
\hline
\end{tabular}


Table 2. Coefficients for the new frequency weighting curves and for ISO 2631-1 Wk.

\begin{tabular}{|c|c|c|c|c|c|c|}
\hline & \multicolumn{5}{|c|}{ Backrest angle } & \multirow{2}{*}{ ISO 2631-1 Wk } \\
\cline { 2 - 6 } & $0^{\circ}$ & $22.5^{\circ}$ & $45^{\circ}$ & $67.5^{\circ}$ & $90^{\circ}$ & 0.4 \\
\hline f1 (Hz) & 6.2 & 5.81 & 5.81 & 5.81 & 4.73 & $1 / \sqrt{ } 2$ \\
\hline Q1 & 1.53 & 1.65 & 1.7 & 1.75 & 0.91 & 100 \\
\hline f2 (Hz) & 200 & 200 & 200 & 200 & 100 & $1 / \sqrt{ } 2$ \\
\hline Q2 & 1.53 & 1.65 & 1.7 & 1.75 & 0.91 & 12.5 \\
\hline f3 (Hz) & 14.47 & 12 & 12 & 12 & 14.47 & 12.5 \\
\hline f4 (Hz) & 8.02 & 8 & 6.98 & 5.96 & 8.16 & 0.63 \\
\hline Q4 & 0.1 & 0.1 & 0.1 & 0.1 & 0.1 & 2.375 \\
\hline f5 (Hz) & 3.13 & 9 & 9.01 & 9.01 & 3.13 & 0.91 \\
\hline Q5 & 0.24 & 0.24 & 0.24 & 0.24 & 0.24 & 3.35 \\
\hline f6 (Hz) & 5.37 & 10.9 & 9.5 & 8.85 & 6.71 & 0.91 \\
\hline Q6 & 0.34 & 0.34 & 0.34 & 0.34 & 0.34 & 1 \\
\hline G & 7.34 & 4.23 & 3.55 & 3.55 & 9.13 & \\
\hline
\end{tabular}


Table 3. Equivalence between the BS and ISO s-domain weighting curve definitions.

\begin{tabular}{|c|c|c|}
\hline $\begin{array}{c}\text { BS parameter } \\
\text { (Eq. 7 to Eq. 9) }\end{array}$ & equivalent to & $\begin{array}{c}\text { ISO parameter } \\
\text { (Eq. 2 to Eq. 6) }\end{array}$ \\
\hline w1 & $\leftrightarrow$ & w1 \\
w2 & $\leftrightarrow$ & w2 \\
w3 & $\leftrightarrow$ & w3 \\
w4 & $\leftrightarrow$ & w4 \\
w5 & $\leftrightarrow$ & w5 \\
w6 & $\leftrightarrow$ & w6 \\
Q1 & $\leftrightarrow$ & Q1 \\
Q2 & $\leftrightarrow$ & Q4 \\
Q3 & $\leftrightarrow$ & Q5 \\
Q4 & $\leftrightarrow$ & Q6 \\
K & & $G \frac{\omega_{5}{ }^{2}}{\omega_{6}{ }^{2}}$ \\
\hline
\end{tabular}


Table 4. Interpolation coefficients.

\begin{tabular}{|c|c|c|c|c|c|}
\hline & $\mathrm{f1}$ & $\mathrm{f} 2$ & f3 & $\mathrm{f} 4$ & f5 \\
\hline $\mathrm{a} 0$ & $6.20 \mathrm{E}+00$ & $2.00 \mathrm{E}+02$ & $1.45 \mathrm{E}+01$ & $9.67 \mathrm{E}+00$ & $3.13 E+00$ \\
\hline a1 & $-2.41 \mathrm{E}-02$ & $1.11 \mathrm{E}+00$ & $-2.56 \mathrm{E}-01$ & $-1.41 \mathrm{E}-01$ & $6.08 \mathrm{E}-01$ \\
\hline a2 & $1.46 \mathrm{E}-04$ & $-9.05 E-02$ & 9.35E-03 & 4.79E-03 & $-2.22 \mathrm{E}-02$ \\
\hline a3 & 9.44E-06 & 2.19E-03 & $-1.45 E-04$ & $-9.44 \mathrm{E}-05$ & $3.43 \mathrm{E}-04$ \\
\hline $\mathrm{a} 4$ & $-1.12 \mathrm{E}-07$ & -1.63E-05 & 8.03E-07 & 6.29E-07 & $-1.91 E-06$ \\
\hline & $\mathrm{f} 6$ & $\mathrm{G}$ & Q1 & Q2 & Q4, Q5, Q6 \\
\hline $\mathrm{a} 0$ & $5.37 \mathrm{E}+00$ & $7.34 \mathrm{E}+00$ & $1.53 E+00$ & $1.53 \mathrm{E}+00$ & No \\
\hline a1 & $6.24 \mathrm{E}-01$ & $-2.92 \mathrm{E}-01$ & $1.86 \mathrm{E}-02$ & $1.86 \mathrm{E}-02$ & interpolation \\
\hline $\mathrm{a} 2$ & $-2.34 \mathrm{E}-02$ & 1.02E-02 & $-1.01 \mathrm{E}-03$ & $-1.01 E-03$ & required \\
\hline a3 & 3.30E-04 & $-1.72 E-04$ & 2.21E-05 & 2.21E-05 & \\
\hline a4 & $-1.61 \mathrm{E}-06$ & $1.08 \mathrm{E}-06$ & $-1.56 \mathrm{E}-07$ & $-1.56 \mathrm{E}-07$ & \\
\hline
\end{tabular}

